\title{
Dinosaur origin of egg color: oviraptors laid blue-green eggs
}

\author{
Jasmina Wiemann ${ }^{\text {Corresp., }}{ }^{1,2}$ ， Tzu-Ruei Yang ${ }^{1}$ ， Philipp N. Sander ${ }^{3,4}$ ， Marion Schneider ${ }^{5}$, Marianne Engeser ${ }^{6}$, \\ Stephanie Kath-Schorr ${ }^{3}$, Christa E. Müller ${ }^{5}$, P. Martin Sander ${ }^{1}$ \\ 1 Division of Palaeontology, Steinmann Institute of Geology, Mineralogy and Palaeontology, University of Bonn, Bonn, Germany \\ 2 Department of Geology \& Geophysics, Yale University, New Haven, Connecticut, United States \\ 3 Life and Medical Sciences Institute, Life and Medical Sciences Institute, University of Bonn, Bonn, Germany \\ 4 Department of Chemistry, University of California, Berkeley, Berkeley, United States \\ 5 Pharmaceutical Institute, Pharmaceutical Chemistry I, University of Bonn, Bonn, Germany \\ 6 Kekulé Institute for Organic Chemistry and Biochemistry, University of Bonn, Bonn, Germany \\ Corresponding Author: Jasmina Wiemann \\ Email address: jasmina.wiemann@yale.edu
}

Protoporphyrin (PP) and biliverdin (BV), give rise to the enormous diversity in avian egg coloration. Egg color serves several ecological purposes, including post-mating signaling and camouflage. Egg camouflage represents a major character of open-nesting birds which accomplish protection of their unhatched offspring against visually oriented predators by cryptic egg coloration. Cryptic coloration evolved to match the predominant shades of color found in the nesting environment. Such a selection pressure for the evolution of colored or cryptic eggs should be present in all open nesting birds and relatives. Many birds are open-nesting, but protect their eggs by continuous brooding, and thus exhibit no or minimal eggshell pigmentation. Their closest extant relatives, crocodiles, protect their eggs by burial and have unpigmented eggs. This phylogenetic pattern led to the assumption that colored eggs evolved within crown birds. The mosaic evolution of supposedly avian traits in non-avian theropod dinosaurs, however, such as the supposed evolution of partially open nesting behavior in oviraptorids, argues against this longestablished theory. Using a double-checking liquid chromatography ESI-Q-TOF mass spectrometry routine, we traced the origin of colored eggs to their non-avian dinosaur ancestors by providing the first record of the avian eggshell pigments protoporphyrin and biliverdin in the eggshells of Late Cretaceous oviraptorid dinosaurs. The eggshell parataxon Macroolithus yaotunensis can be assigned to the oviraptor Heyuannia huangi based on exceptionally preserved, late developmental stage embryo remains. The analyzed eggshells are from three Late Cretaceous fluvial deposits ranging from eastern to southernmost China. Reevaluation of these taphonomic settings, and a consideration of patterns in the porosity of completely preserved eggs support an at least partially open nesting behavior for oviraptorosaurs. Such a nest arrangement corresponds with our reconstruction of blue-green eggs for oviraptors. According to the sexual signaling 
hypothesis, the reconstructed blue-green eggs support the origin of previously hypothesized avian paternal care in oviraptorid dinosaurs. Preserved dinosaur egg color not only pushes the current limits of the vertebrate molecular and associated soft tissue fossil record, but also provides a perspective on the potential application of this unexplored paleontological resource. 


\section{Dinosaur Origin of Egg Color: Oviraptors Laid Blue-Green Eggs}

2

3 Jasmina Wiemann ${ }^{1,2}$, Tzu-Ruei Yang ${ }^{1}$, Philipp N. Sander ${ }^{3,4}$, Marion Schneider ${ }^{5}$, Marianne

4 Engeser $^{6}$, Stephanie Kath-Schorr ${ }^{3}$, Christa E. Müller ${ }^{5}$, \& P. Martin Sander ${ }^{1}$

1. Division of Palaeontology, Steinmann Institute of Geology, Mineralogy and Palaeontology, University of Bonn, Bonn, Germany

2. Department of Geology \& Geophysics, Yale University, New Haven, Connecticut, United States

3. Life and Medical Sciences Institute, Life and Medical Sciences Institute, University of

18 Corresponding authors

19 Jasmina Wiemann

20 jasmina.wiemann@yale.edu

21 Tzu-Ruei Yang

22 lereage@gmail.com

23 


\section{ABSTRACT}

28 Protoporphyrin (PP) and biliverdin (BV), give rise to the enormous diversity in avian egg coloration. Egg color serves several ecological purposes, including post-mating signaling and camouflage. Egg camouflage represents a major character of open-nesting birds which accomplish protection of their unhatched offspring against visually oriented predators by cryptic egg coloration. Cryptic coloration evolved to match the predominant shades of color found in the nesting environment. Such a selection pressure for the evolution of colored or cryptic eggs should be present in all open nesting birds and relatives. Many birds are open-nesting, but protect their eggs by continuous brooding, and thus exhibit no or minimal eggshell pigmentation. Their closest extant relatives, crocodiles, protect their eggs by burial and have unpigmented eggs. This phylogenetic pattern led to the assumption that colored eggs evolved within crown birds. The mosaic evolution of supposedly avian traits in non-avian theropod dinosaurs, however, such as the supposed evolution of partially open nesting behavior in oviraptorids, argues against this long-established theory. Using a double-checking liquid chromatography ESI-Q-TOF mass spectrometry routine, we traced the origin of colored eggs to their non-avian dinosaur ancestors by providing the first record of the avian eggshell pigments protoporphyrin and biliverdin in the eggshells of Late Cretaceous oviraptorid dinosaurs. The eggshell parataxon Macroolithus yaotunensis can be reliably assigned to the oviraptor Heyuannia huangi based on exceptionally preserved, late developmental stage embryo remains. The analyzed eggshells are from three Late Cretaceous fluvial deposits ranging from eastern to southernmost China. Reevaluation of these taphonomic settings, and a consideration of patterns in the porosity of completely preserved eggs support an at least partially open nesting behavior for oviraptorosaurs. Such a nest arrangement corresponds with our reconstruction of blue-green eggs for oviraptors. According to the sexual signaling hypothesis, the reconstructed blue-green eggs support the origin of previously pushes the current limits of the vertebrate molecular and associated soft tissue fossil record, but also provides a perspective on the potential application of this unexplored paleontological resource. 


\section{INTRODUCTION}

Birds offer the most diverse displays of color and shape among modern vertebrates (Stoddard \& Prum, 2011). In contrast to their closest modern relatives, the crocodiles, avian eggs range widely in size and shape, and the avian key innovation seems to be variation in color (Cassey et al., 2012). Nature`s repertoire ranges from immaculate (homogeneously colored) reddish brown and white eggs in chicken (Gallus domesticus), to light beige with dark brown maculation (speckling) in the oystercatcher (Haematopus ostralegus), to light blue in the American robin (Turdus migratorius), to the intensive bluish-green of emu eggs (Dromaius novaehollandiae) at the end of the spectrum (Cassey et al., 2012).

All other amniotes, including non-avian reptiles and monotreme mammals, lack eggshell color (Packard \& Seymour, 1997). Non-avian amniotes can protect their eggs by burying them (Leighton et al., 2009), or by continuously guarding the nest (Komdeur et al., 1999). Colored eggs are present in most modern birds which build open nests, as the eggs are vulnerable due to periods without parental guarding (Komdeur et al., 1999; Gillis et al., 2012). Birds with biparental brooding behavior minimize the periods during which a clutch is unattended and vulnerable, and sometimes reduce egg coloration (Komdeur et al., 1999). Complete reduction of eggshell coloration is observed in many cavity nesting and cave-breeding birds (Hewitson, 1864) confirming the visual signaling component of egg color function (Castilla et al., 2007). Visual signaling resulting in camouflage of an egg clutch is largely dependent on eggshell coloration relative to the color shade of the nesting background (Wallace, 1890; Stoddard et al., 2016). Such negative signaling also offers protection against brood parasitism because of, e.g., elaborate egg color innovations that allow recognition of parasite eggs among the clutch (Newton, 1896). In addition to signaling, numerous other functions of egg color pigments have been proposed, such as antimicrobial effects (Ishikawa, 2010), protection from solar radiation (Lahti, 2008), and eggshell mechanical reinforcement (Gosler, Higham \& Reynolds, 2005). In a phylogenetic analysis of egg shell coloration and color patterning, Kilner (2006) concluded that the ancestral egg color of avian of extant birds was white, and that egg coloration evolved multiple times within crown birds (see Kilner, 2006).

This phylogenetic inference ignores the fact that many birds with white eggs, including ostrich (Struthio), rhea (Rhea) and elephant bird (Aepyornis) contain minor amounts of eggshell 
87 pigment, and that their reduced pigment most likely represents an evolutionary reaction to the 88 brooding-based reduced selection pressure on coloring their eggs (Kennedy \& Vevers, 1975). 89

We hypothesize egg coloration evolved after the switch from burying eggs to building an 90 open and exposed nest (consistent with Gillis et al., 2012). Selection for egg color would only 91 have occurred after the eggs themselves became visible to parents, conspecifics, predators, or 92 parasites (Kilner, 2006).

While most dinosaurs buried their eggs (reviewed by Varricchio \& Jackson, 2016), there 94 is ample evidence that bird-like, non-avian eumaniraptoran dinosaurs, i.e., Oviraptorosauria, 95 96 Dromaeosauridae, and Troodontidae, built open ground nests with at least partially exposed eggs (Varricchio \& Jackson, 2016, Norell et al., 1995). Partial exposure accounts for the arrangement of their strongly elongated eggs stacked and partially buried almost vertically in the nest material in circular layers either with (seemingly primitive) or without (derived) an empty space in the center of the nest (Norell et al., 1995). Late Cretaceous oviraptorosaurid eggs from China and Mongolia (Norell et al., 1995; reviewed in Varricchio \& Jackson 2016) are frequently preserved, and because they are laid in exposed, partially open nests (Norell et al., 1995), they may have been pigmented like many bird eggs.

Only two chemical compounds act as avian eggshell pigments and give rise to virtually all observed bird egg colors and patterns-the tetrapyrrols protoporphyrin (PP) and biliverdin (BV) (Kennedy \& Vevers, 1975). Both are participants in the vertebrate heme cycle: protoporphyrin is a reddish-brown heme precursor, while biliverdin is a blue-greenish heme catabolite (Ryter \& Tyrrell, 2000). In contrast to the linear BV, the cyclic PP exhibits a stronger resonance stabilization (Falk, 1964). Due to their different metabolic functions, PP and BV have distinctively different chemical properties: while PP is lipophilic and rather unreactive, BV is much more reactive due to its hydrophilic, oxidated, linear arrangement (Gorchein et al., 2009).

$111 \mathrm{BV}$ is distributed throughout the entire thickness of the prismatic layer in eggshells, most

112 probably linked to matrix proteins, while PP is currently thought to be present in high 113 concentrations only in the outermost eggshell cuticle layer (Wang et al., 2009). Related avian

114 pigments are incorporated into integumentary structures, such as, for example, the PP relative 115 uroporphyrin III which occurs as red turacine pigment in the feathers of herbivorous, 116 musophagid birds (Rimington, 1939). Structurally, the two avian eggshell pigments show a 117 similarity to the most common vertebrate pigments eu- and pheomelanin, in being $\mathrm{N}$ - 
118 heterocycles (Watt et al., 2009) although their origins are very different in vertebrate secondary

119 metabolism (Kubo \& Furusawa, 1991).

120 In terms of pigment taphonomy, the oldest confirmed record of eggshell PP and BV

121 traces is in subfossil moa eggs from New Zealand (Igic et al. 2009) which demonstrates their

122 preservation potential on a time scale of $10^{3}$ years, but also the loss of the more labile BV

123 through time due to degradation processes, dissolution and transport via percolating aqueous

124 fluids. Other related biomolecules with a reported fossil record are hemes (Greenwalt et al.,

125 2013), and chlorophylls (Leavitt, 1993). Both have been identified with minimal or no diagenetic

126 alteration from Mesozoic and Cenozoic fossil deposits, supporting the possibility of eggshell

127 pigment preservation in fluvial or alluvial oxidative deposits such as those from eastern and

128 southern China.

129 We identified unmodified, preserved PP and BV eggshell pigments in all three

130 oviraptorid samples and proved that these eggshells were the sole source of pigments by

131 demonstrating the absence of BV and PP in the investigated sample of adjacent sediment. We

132 also provide support for the preservation of dinosaur eggshell cuticle (previously suggested by

133 Mikhailov, 1991; Schweitzer et al. 2002; Varricchio and Jackson 2004) based on cuticular PP

134 storage. These observations phylogenetically extend the presence of an avian-like eggshell

135 pigmentation back to oviraptorids. Using the known concentrations of our commercial pigment

136 standards and PP and BV concentrations in emu eggshell as a sensitivity control and quality

137 marker for our analytic system, we reconstructed a visually evident blue-green egg color for

138 Heyuannia incorporating experimental and taphonomic corrections. Our eggshell zonal porosity

139 reevaluation reconstructed an at least partially open nest for the oviraptorid Heyuannia huangi

140 (based on Varricchio et al. 2008; Deeming, 2006; see Supplemental Information).

142 MATERIALS AND METHODS

143 Institutional abbreviations

144 NMNS: National Museum of Natural Sciences, Taichung, Taiwan

145 PFMM: Paleowonders Fossils and Mineral Museum, Taipei, Taiwan

146 STIPB: Steinmann Institute of Geology, Mineralogy, and Paleontology, Division of

147 Paleontology, University of Bonn, Bonn, Germany

148 ZFMK: Zoologisches Forschungsinstitut und Museum Alexander Koenig, Bonn, 


\section{Extant eggshell material}

152 The emu eggshells (Dromaius novaehollandiae) were produced by captive birds and are 153 stored in the ZFMK collections (ZFMK uncat.). Emu eggshell is reported to contain minimal

154 amounts of PP in addition to some of the highest naturally occurring amounts of BV (Gorchein et 155 al., 2012).

\section{Fossil eggshell material}

158 We sampled three oviraptorid Macroolithus yaotunensis eggs from the collections of the NMNS and STIPB covering three geographically and taphonomically distinct Chinese deposits. Investigated specimens were collected in the Liguanqiao Basin near Nanyang in the province of Henan (STIPB E54/1), from the Hongcheng Basin in the province of Jiangxi (NMNS CYN2004-DINO-05/I), and the Nanxiong Basin in province of Guangdong (STIPB E54/3). Detailed descriptions of the localities in context of geological and taphonomic settings are included in the Supplemental Information. Macroscopically, all oviraptorid eggshell samples had a blackish to blackish-brownish (after cleaning them from adherent sediment) color, revealing a very subtle shimmer of blue-green at angled light conditions.

Historically, samples derived from the Liguanqiao Basin are Late Cretaceous in age and derived from the fluvial/alluvial deposits (red sandstones) of the Hugang Formation. They have been housed in STIPB since 1983 and were previously described by Erben (1995). Preserved oviraptorid eggs from the Hongcheng Basin in the province of Jiangxi were obtained from the

171 Late Cretaceous Tangbian Formation which comprises fluvial red sandstones. The Hongcheng

172 Basin and the Nanxiong Basin may belong to the same extended basin complex (Liu, 1999). The

173 Late Cretaceous strata of the Nanxiong Basin are divided into the Yuanpu Formation and the 174 overlying Pingling Formation. The Yuanpu Formation, which might be correlated with the fossil175 rich Mongolian Djadochta Formation, yielded our eggshell samples from alluvial sediments (red silt-sandstones), and is dated as Maastrichtian in age (Zhao et al., 1991). 
177

178

179

180

181

182

183

184

185

186

187

188

189

190

191

192
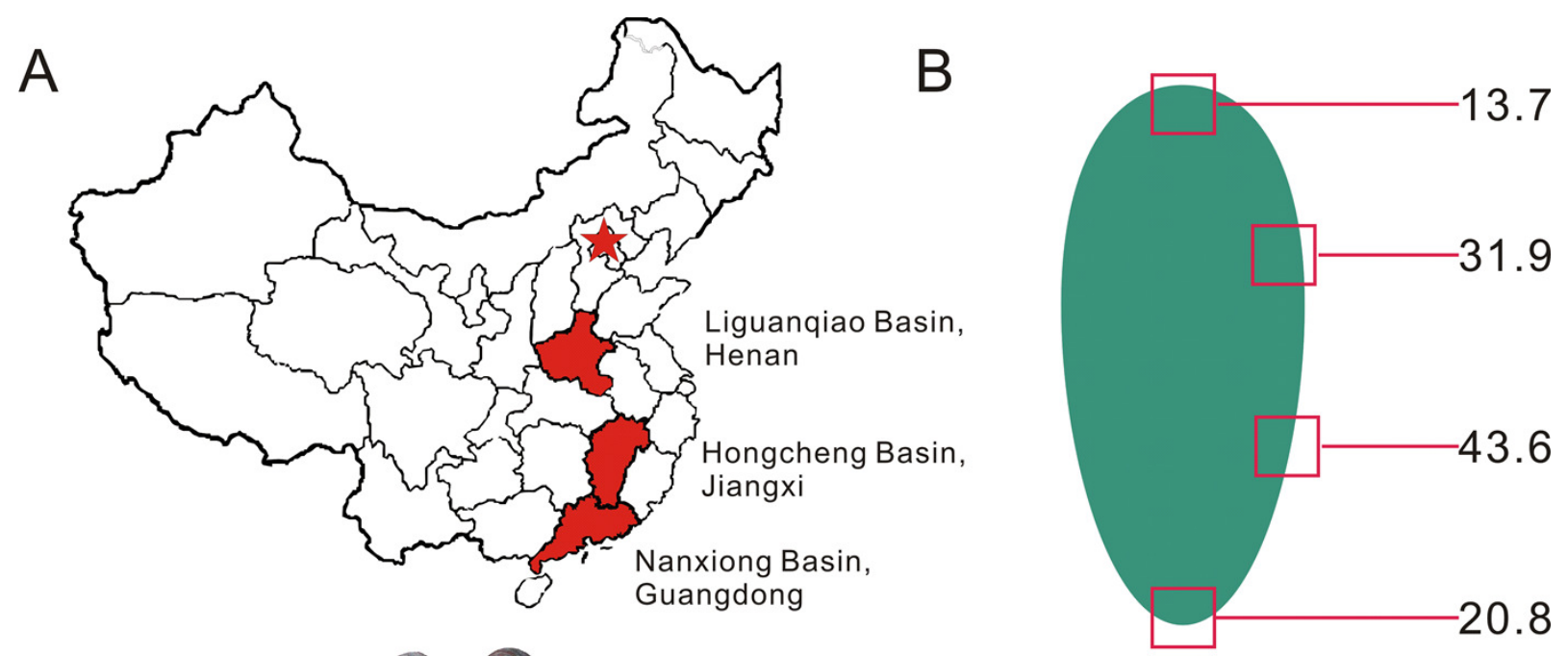

C

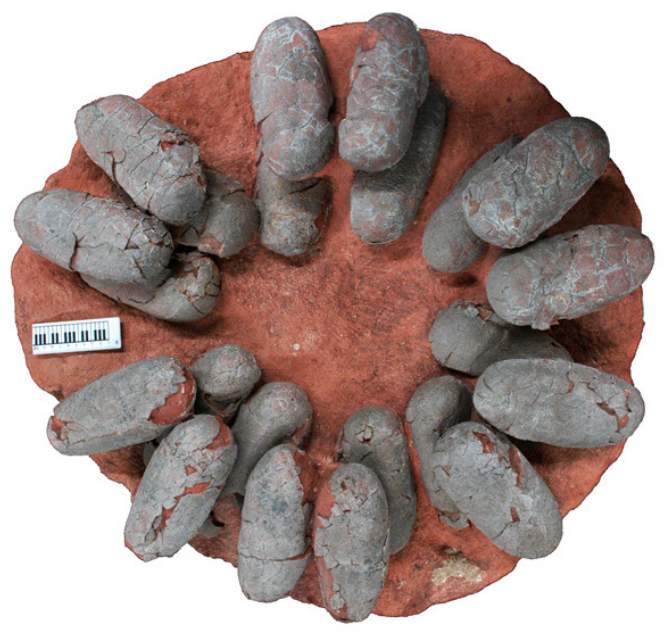

D

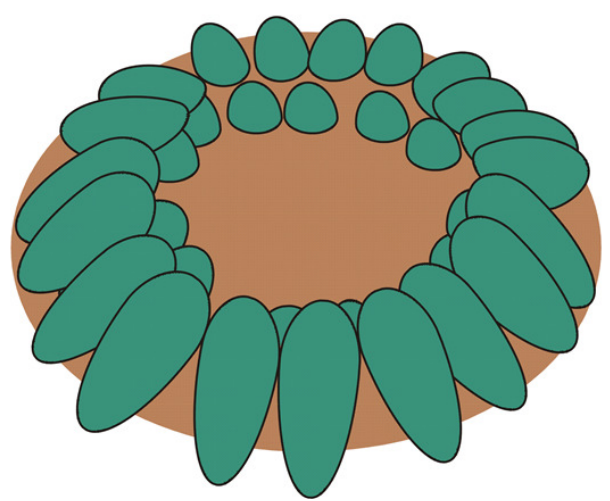

Figure 1 (A) Pair of oviraptorid Heyuannia eggs (NMNS CYN-2004-DINO-05) from the Chinese province of Jiangxi before sampling. Porosity measurements and calculations of water vapor conductance are based on these eggs. Pieces of eggshell from each of the four zones depicted in (B) were used in porosity measurements. (B) Egg model separated into four zones used for zonal porosity measurements. Therefore, double half-prolate spheroids and cone models of the idealized egg were used to estimate the zonal surface areas to eventually approximate water vapor conductance. Zone 1 represents the blunt end of the egg, zones 2 and 3 the mid portions, zone 4 represents the pointed end of the egg.

One of two preserved complete eggs (Fig. 1A) from the Chinese province of Jiangxi (NMNS CYN-2004-DINO-05) which were previously assigned to the oviraptorid egg parataxon Macroolithus yaotunensis was sampled over four zones of the egg (Fig. 1B, Fig. 2), prepared for histology, and then used for porosity measurements (see Supplemental Information). These four zones represent the blunt, middle, and acute parts of the egg, and were separated to approach zonal differences in porosity values which were tested for maximum porosity at the mid portions to indicate egg storage in an open nest (based on Varricchio et al. 2008). Measured porosity 
193 values were compared to published dinosaur and avian porosity patterns and used to calculate the eggshell water vapor conductivity. Samples for chemical analyses were taken separately.

195 Sediment adhering to the complete eggs (NMNS CYN-2004-DINO-05/I) was sampled

196 additionally to confirm that we are not dealing with wholesale sample contamination. A single sediment sample (red silty sandstone) was available to test against wholesale contamination with BV and PP of the sample since only the complete oviraptorid eggs from the province of Jiangxi provided original, attached matrix sediment. The two-remaining fossil oviraptor eggshell samples represent isolated fragments freed of original matrix.

201
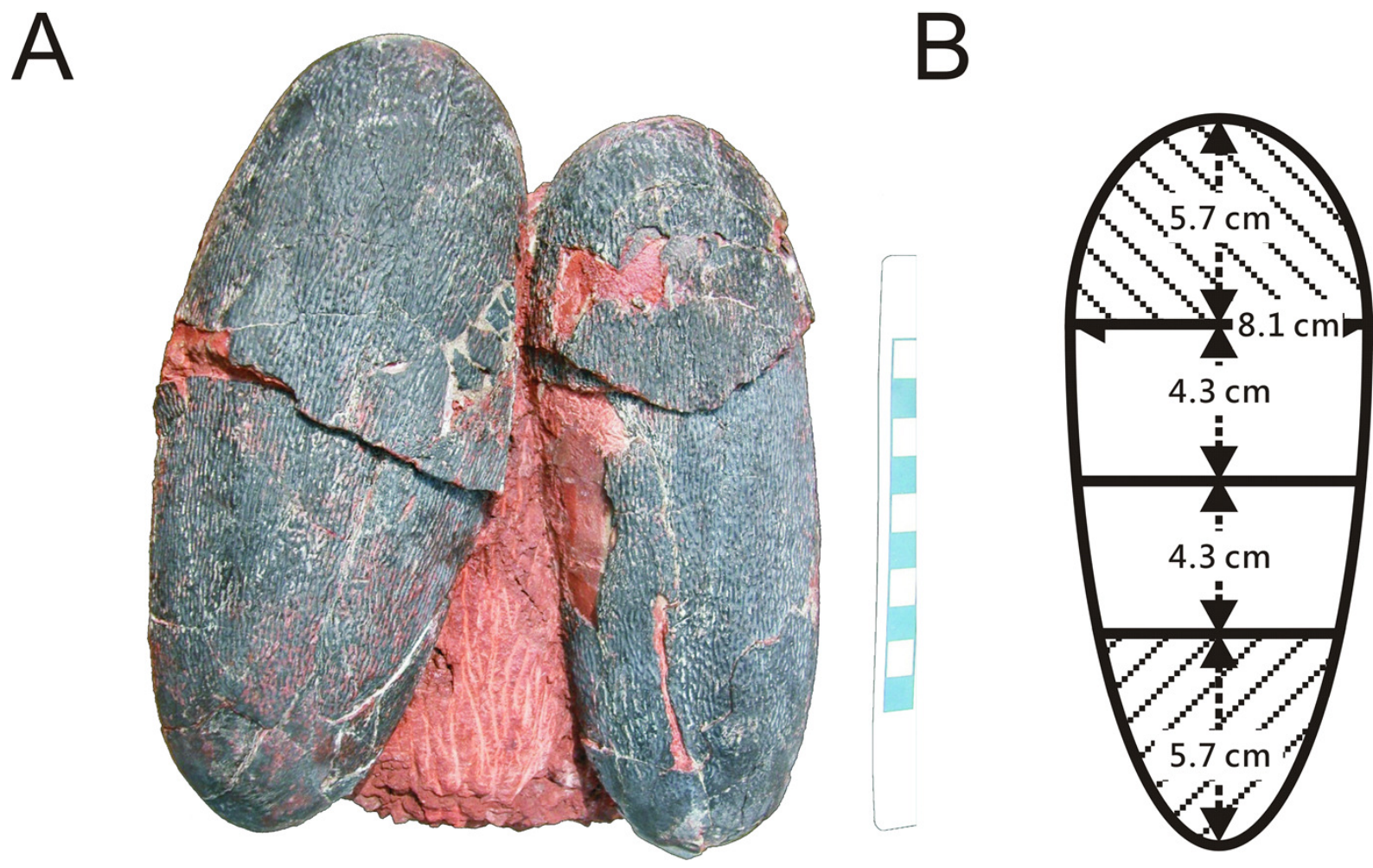

Figure 2 Provenance of Heyuannia eggshell, reconstructed zonal egg water vapor conductance, oviraptor clutch structure, and corrected, reconstructed egg color. (A) Geographical map of China. The capital city, Beijing, is indicated by the red star. Red shaded provinces indicate the three different localities where the specimens were collected: the Liguanqiao Basin in Henan, the Hongcheng Basin in Jiangxi, and the Nanxiong Basin in Guangdong (see SI). (B) The reconstructed color and average zonal water vapor conductance of the left Jiangxi Heyuannia huangi egg (NMNS CYN-2004-DINO-05/I) calculated from BV and PP concentrations and porosity measurements (see Supplemental Information). (C) Top view of 
210 an oviraptor clutch (PFMM 0010403018). This clutch illustrates how eggs are arranged in pairs with their

211 blunt ends pointing to the clutch center. The eggs are arranged in layers separated by sediment. (D)

212 Reconstruction of a partially open oviraptorid nest. Note that the original inclination of the eggs would

213 have been steeper than their preserved attitude (C) due to sediment compaction.

214

215

216

217 Methods

218 We used two commercial standards (biliverdin dihydrochloride and protoporphyrin IX,

219 purchased from Sigma Aldrich), one extant bird eggshell sample (emu), the three fossil

220 Heyuannia huangi eggshell samples, and one sediment sample (reddish sandstone) for High

221 Performance Liquid Chromatography coupled to Electrospray Ionization Quadrupole Time-of-

222 Flight Mass Spectrometry (HPLC ESI Q-ToF MS).

223

The basis for this sample selection was (1) to demonstrate reproducibility in three fossil

224 eggshell samples, (2) to exclude the possibility of wholesale contamination due to sample or

225 system exogenous PP or BV input by analyzing sediment adhering to a sample of eggshell, (3) to provide a sensitivity control and quality marker of the analytical routine based on precise detection and quantification of emu eggshell (ranging from the upper (BV) to the lower (PP) detection limit in terms of pigment concentrations), and (4) to generate a calibrated concentration signal for quantification based on the known concentrations of the commercial standards.

Adhering sediment and other superficial contaminations were chemically removed from all eggshell samples by a boosted decalcification of the outermost sample surfaces. $500 \mu \mathrm{L}$ of disodium EDTA solution (100 mg/mL), adjusted to a $\mathrm{pH}$ of 7.2, were added to the $180-562 \mathrm{mg}$ eggshell samples and sediment control sample, each of which was stored in $1 \mathrm{~mL}$ Eppendorf tube. Samples were incubated for $5 \mathrm{~min}$ and then transferred to fresh Eppendorf tubes. The decalcification residue was discarded.

Pigment decalcification was performed immediately after preliminary cleaning of the samples. The three oviraptorid eggshell samples, the emu eggshell, and the sediment control sample were incubated again in the EDTA solution which was already used for initial cleaning, this time for $5 \mathrm{~min}$. During this $5 \mathrm{~min}$, the sample tubes were vortexed three times for $1 \mathrm{~min}$. Vortexing was performed with uncapped tubes to allow outgassing of the carbon dioxide generated. After 5 min of incubation in the EDTA decalcification solution, all sample tubes were centrifuged at 15,000g for $1 \mathrm{~min}$. After centrifuging, the supernatant solutions were collected in 
243 separate tubes, while the decalcified sample precipitates were filled up with fresh EDTA solution

244 from the stock. Incubation of 5 min followed, including vortexing 3x in uncapped tubes, as in the

245 previous step. The samples were centrifuged again at $15,000 \mathrm{~g}$ for $1 \mathrm{~min}$, supernatants were

246 collected, and the precipitates filled up with fresh EDTA solution. As in the previous step,

247 incubation of 5 min including vortexing of the uncapped sample tubes followed. After a final

248 round of centrifuging for $1 \mathrm{~min}$, supernatant solutions were collected, and the partially

249 decalcified precipitates were used for the final pigment extraction. $1 \mathrm{~mL}$ of acetonitrile/acetic

250 acid $(4: 1, v / v)$ was added to the decalcified sample pellets for $10 \mathrm{~min}$ of incubation, including 2

251 min of vortex-mixing. Afterwards the sample tubes were centrifuged at 15,000g for 2 min, and

252 the supernatant solution holding the pigment extract were transferred into fresh Eppendorf tubes,

253 and stored in a dark environment at $4^{\circ} \mathrm{C}$. The commercial standards were dissolved in the same

254 acetonitrile-acetic acid solution $(4: 1, v / v)$ and stored with the sample pigment extracts.

255 The filtered extracts and commercial standard solutions were stored less than $24 \mathrm{~h}$ before

256 they were injected into an HPLC Dionex Ultimate 3000 (Thermo Scientific) separating sample

257 compounds by using a EC50/2 Nucleodur C18 Gravity $3 \mu \mathrm{m}$ column (Macherey-Nagel).

258 Reverse-phase HPLC was run at a flow rate of $0.3 \mathrm{~mL} / \mathrm{min}$. HPLC was started at $90 \% \mathrm{H}_{2} \mathrm{O}$

259 containing $0.1 \%$ acetic acid. The gradient started after 1 min and reached $100 \%$ acetonitrile after

$26014 \mathrm{~min}$. For additional $7 \mathrm{~min}$, the column was flushed with $100 \%$ acetonitrile (containing $0.1 \%$

261 acetic acid). For the biliverdin analysis, $15 \mu \mathrm{L}$ sample solution were injected, and $20 \mu \mathrm{L}$ for the

262 protoporphyrin detection. 2 min of washing runs between each sample extract cleaned the entire

263 system. The liquid chromatography system was coupled to a micrOTOF-Q mass spectrometer

264 (Bruker) with an electrospray ionization (ESI) source inducing positive ionization.

265 Data were collected in positive full scan MS mode over the range of $50-1000 \mathrm{~m} / \mathrm{z}$, using

266 a capillary voltage of $4.5 \mathrm{kV}$ and an end plate offset of $-500 \mathrm{~V}$. The dry heater of the ESI source

267 was set at $200^{\circ} \mathrm{C}$. Nitrogen desolution and nebulizer gas flow was $10.0 \mathrm{~L} / \mathrm{min}$; the nebulizer was

268 run at 2.2 bar. Time-of-Flight (TOF) detection allowed the determination of the accurate masses

269 of biliverdin and protoporphyrin.

270

271

\section{RESULTS}

272

273

We reliably identified both $\mathrm{BV}$, as $[\mathrm{M}+\mathrm{H}]^{+}$with $583.2520 \mathrm{~m} / \mathrm{z}$ (calculated mass:

$583.2551 \mathrm{~g} / \mathrm{mol}$ ) after $8 \mathrm{~min}$ retention time, and $\mathrm{PP}$, as $[\mathrm{M}+\mathrm{H}]^{+}$complex with $563.2623 \mathrm{~m} / \mathrm{z}$ 
274 (calculated mass: $563.2653 \mathrm{~g} / \mathrm{mol}$ ) after 14 min retention time (Fig. 3A) in the commercial 275 standard solutions, the emu eggshell, and the three fossil oviraptorid eggshell samples. The 276 commercial standard solutions of known concentrations were used to identify the chemotrait277 specific, diagnostic retention times for BV and PP on the chromatographic column. Elution of 278 BV was consistent after 8 min, while elution of PP delayed consistently until 14 min of the run 279 mobile phase gradient (consistent with Igic et al., 2009). A second compound-diagnostic trait 280 was provided by ionization after elution from the chromatographic column, followed by exact mass determination of the $[\mathrm{M}+\mathrm{H}]^{+}$ion complexes. Differing behavior of $\mathrm{BV}$ and PP native to eggshells compared to commercially purified $\mathrm{BV}$ and $\mathrm{PP}$ was ruled out by identical retention times, numbers of isoforms/tautomers, and exact mass peaks of emu eggshell $\mathrm{BV}$ and PP and the commercial standard solutions. Furthermore, maximum sensitivity of the HPLC ESI MS system was demonstrated by precise detection of pigment concentrations in the emu eggshell solution which approached the upper (BV) and the lower (PP) detection limits. The extracted ion chromatograms (EICs) for BV and PP obtained from the sediment sample whole ion mass spectrum yielded signals within broader tolerances of the BV and PP exact masses, but no peaks corresponding to the commercial standard calibrated retention times were identified. Absence of a diagnostic mass peak after 8 min retention time on the column for BV, and after $14 \mathrm{~min}$ retention time on the column for $\mathrm{PP}$, is a significant demonstration of absence of trace amounts $\mathrm{BV}$ and PP in the sediment sample. Thereby, contamination of the samples or the detection system was excluded and originality of the detected pigments in the oviraptorid eggshell samples is guaranteed.

Quantification of the detected pigment concentrations based on commercial standard calibration was determined by application of an experiment-empirical correction for the extraction loss of BV due to its increased hydrophily of the fossil oviraptor eggs. We found the highest preserved concentrations of BV in the eggshells from Henan $(6 \mathrm{nmol} / \mathrm{g})$, followed by the eggshells from Jiangxi $(2 \mathrm{nmol} / \mathrm{g})$ and those from Guangdong $(1 \mathrm{nmol} / \mathrm{g})$. The preserved PP concentrations ranged from $2 \mathrm{nmol} / \mathrm{g}$ in both the Henan and Jiangxi eggshells to 1 $\mathrm{nmol} / \mathrm{g}$ in the Guangdong eggshells. Our empirical correction applied to the fossil eggshell

302 samples yielded very realistic pigment concentration estimates for the emu eggshell of $2 \mathrm{nmol} / \mathrm{g}$

$303 \mathrm{PP}$, and $266 \mathrm{nmol} / \mathrm{g} \mathrm{BV}$ which fall into the reported range of emu eggshell pigment concentrations in the scientific literature (Table S1). The bluish shimmer of the fossil oviraptorid 
305 eggshells suggests generally higher BV concentrations than those we detected, as also found in a

306 similar study on pigment preservation in subfossil moa eggshells using the same methodology.

307 The color of the fossil eggs suggested higher BV concentrations than the authors managed to

308 detect. Taken together, our study and the study by Igic et al. (2009) imply that bluish or greenish

309 coloring degradation products of BV remain which therefore shows slightly different chemical

310 properties and different exact masses, and is thus not detected by an LC MS system targeting

311 unmodified compounds measurable against commercial standards.

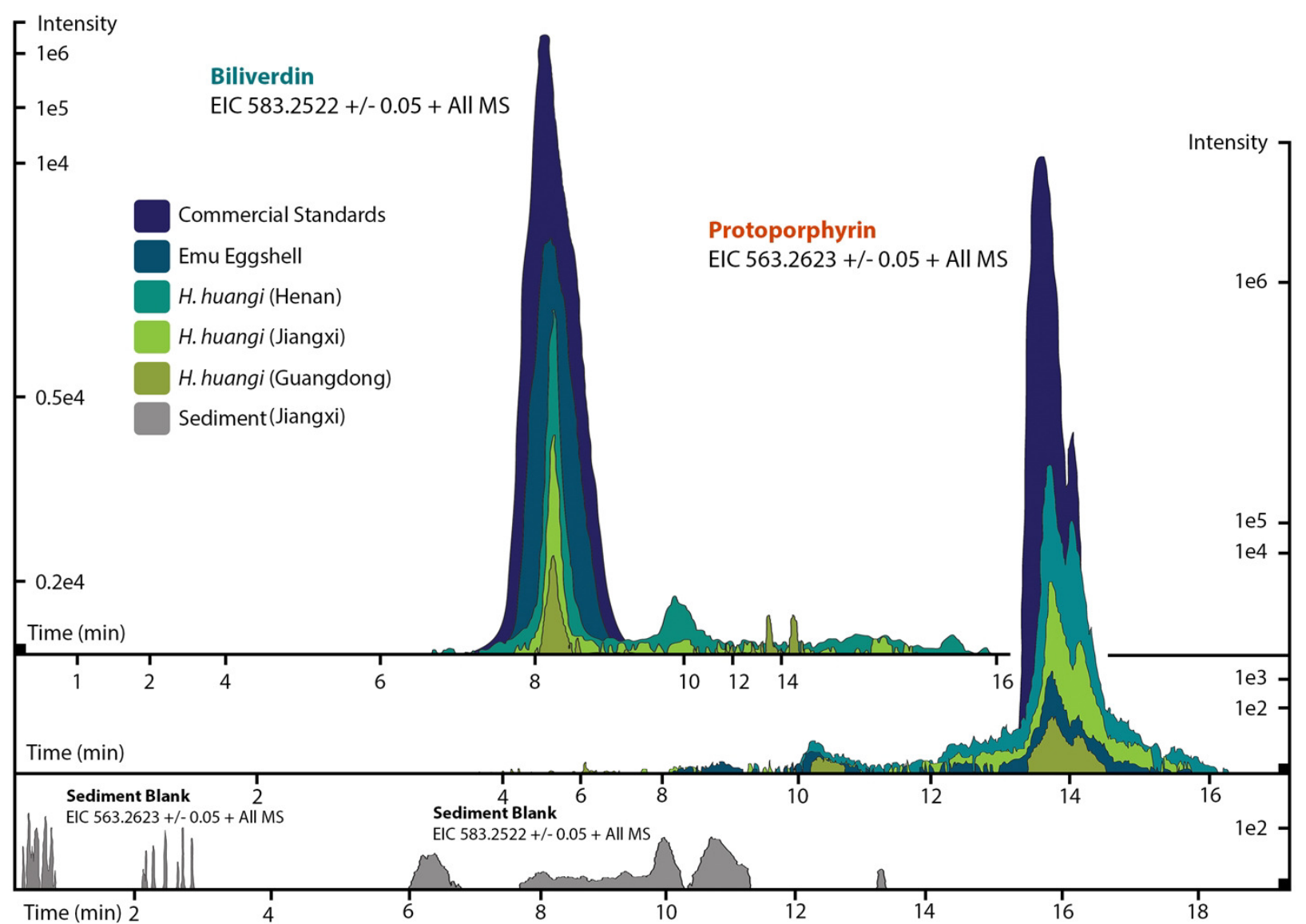

313 Figure 3 ESI (+) MS extracted ion chromatograms (EICs) for mass $583.2520 \pm 0.01 / 0.05 \mathrm{~m} / \mathrm{z}$, indicative 314 of BV, and mass $563.2653 \pm 0.01 / 0.05 \mathrm{~m} / \mathrm{z}$, indicative of PP. We identified BV and PP by retention time, 315 exact mass and isoform/tautomer separation. EICs for $583.2520 \pm 0.01 / 0.05 \mathrm{~m} / \mathrm{z}$ are depicted for the 316 commercial BV standard, emu eggshell, extracts of Heyuannia huangi eggshells derived from the Chinese 317 provinces Henan, Jiangxi, and Guangdong and the sediment control extract from Jiangxi. Unmodified BV 318 elutes after 8 min retention time, and was proven present for the biliverdin commercial standard, the emu 319 eggshell, and the three oviraptorid eggshells. The sediment sample was used as control for contamination, 320 and its EIC does not show a peak after 8 min retention time, proving the absence of biliverdin in the 321 sediment sample and the originality of biliverdin detected for the eggshell samples. (B) EICs for 563.2653 $322 \pm 0.01 / 0.05 \mathrm{~m} / \mathrm{z}$ are depicted for the commercial PP standard, emu eggshell, Heyuannia huangi eggshell 
323 derived from the Chinese provinces Henan, Jiangxi, and Guangdong, and the sediment sample from

324 Jiangxi. Unmodified PP elutes after $14 \mathrm{~min}$ and was proven present for the PP commercial standard, the

325 emu eggshell, and the fossil oviraptorid eggshells. There is no peak in the PP EIC for the sediment sample

326 after $14 \mathrm{~min}$, what proves the absence of PP in the sediment control sample, and the originality of PP in

327 the eggshell samples. Peak intensity correlates with pigment concentrations in the extracts.

328

329

To demonstrate the perceivability of a visual color signal based on the detected pigment

330 concentrations in the oviraptorid eggshells, we plotted our pigment concentrations into the

331 comprehensive pigment concentration-color matrix of Cassey et al. (2012). Our three dinosaur

332 egg color data points fall in the visibly olive-green color range between Haliaetus albicilla and

333 Circus aeruginosus (Cassey et al. 2012). They plot in the cluster of unspotted eggs, suggesting

334 an immaculate, homogenous coloration. No patterns were visible in the fossil eggs (Fig. 1).

335 Since the preserved fossil oviraptor eggshell color suggests originally higher BV

336 concentrations, taphonomy needs to be considered to generate a realistic, native oviraptor egg

337 color reconstruction. Because BV is more reactive and more hydrophilic, and thus soluble in

338 sediment-percolating aqueous fluids, the concentrations of unmodified, preserved pigments after

339 at least 66 million years of sedimentary burial are much more likely to be significantly lowered

340 than those of the more stable, hydrophobic PP (Falk, 1964). Therefore, the taphonomic

341 projections of our preserved pigment concentrations in the avian egg color space (Cassey et al.

342 2012) realistically lift the investigated oviraptor egg colors significantly towards much higher

343 BV values, while the shift towards increased PP values would be only minimal. However, our

344 fossil oviraptor eggs would remain deeply nested within the area of unspotted eggs (based on

345 Cassey et al. 2012). Such an additional taphonomic correction of the reconstructed egg color

346 approximates an intensively blue-greenish oviraptorid egg color. Whether the differences in

347 preserved pigment concentrations between the three fossil oviraptor egg samples from different

348 localities reflect intraspecific variation in egg color or different taphonomic conditions in the

349 deposits cannot be reliably assessed at this point and requires future investigations. Since these

350 differences in preserved pigment concentrations in the oviraptorid eggshells affect the BV values

351 much stronger (range $6-1 \mathrm{nmol} / \mathrm{g}$ ) than they affect the PP values (range $2-1 \mathrm{nmol} / \mathrm{g}$ ), we

352 assume that differences in color are more likely to be taphonomic. In vivo intraspecific variation

353 of egg color would most likely affect BV and PP concentrations equally, while taphonomic

354 effects affect BV concentrations much stronger than PP concentrations (Falk et al., 1964). Also,

355 the original egg color is overprinted by a generally blackish-brownish hue (Fig. 1). This 
356 brownish discoloration traces back to preserved, oxidatively crosslinked eggshell organic matrix 357 proteins of the AGE/ALE-type (Wiemann et al. 2016).

358

359

360

361

362

363

364

365

366

367

368

369

370

371

372

373

374

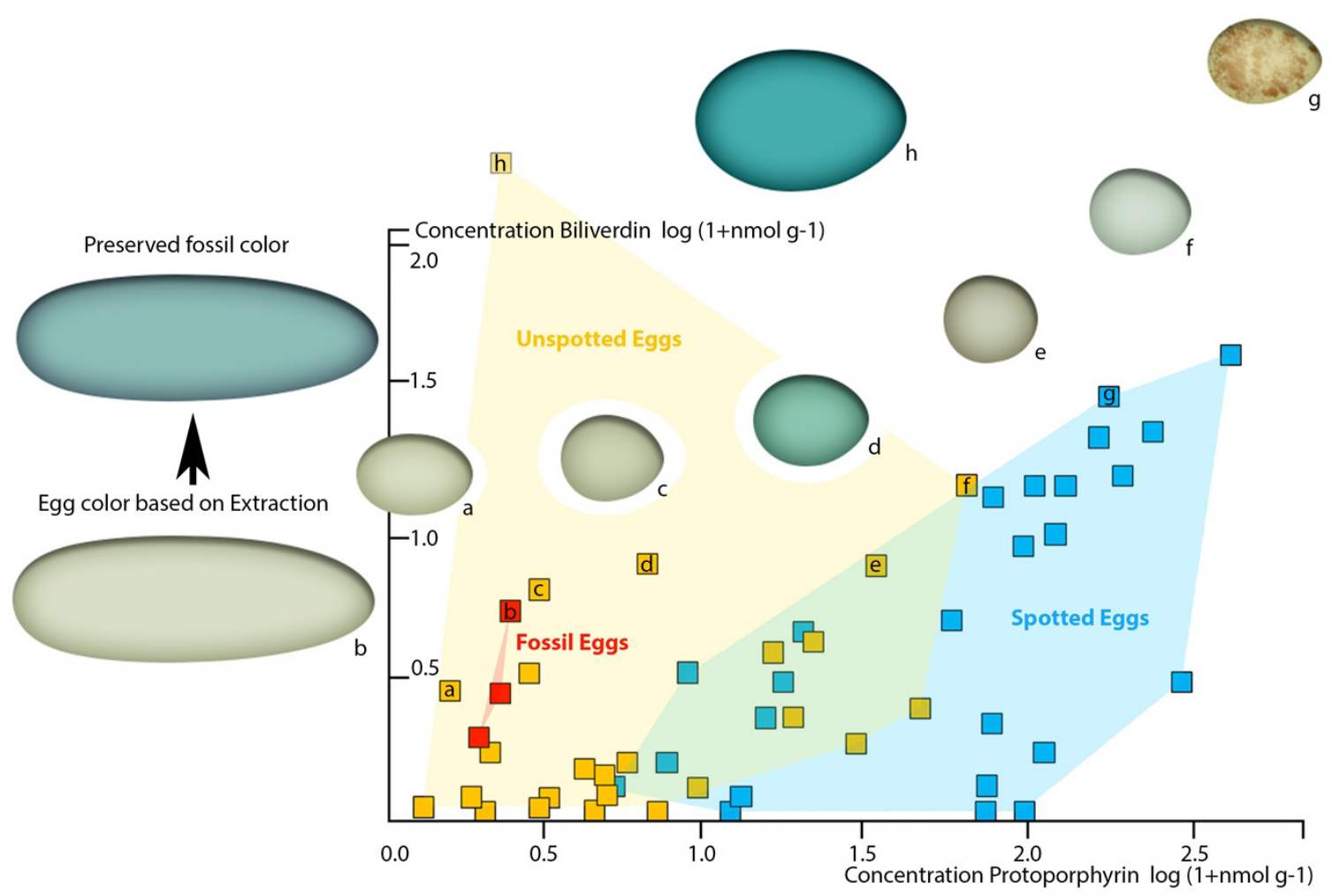

Figure 4 Plot of oviraptor egg and different avian egg biliverdin concentrations against their protoporphyrin concentrations with example for the overall color impression based on the dataset published by Cassey et al. 2012. Avian eggs cluster together moderately separated into unspotted (yellow cluster, yellow squares) and spotted (blue cluster, blue squares) eggs. Fossil oviraptorid eggs span a color space (red cluster) and are represented by red squares, all nested within definitely unspotted eggs. The color examples extracted from Cassey et al. 2012 indicated for the preserved oviraptor egg pigments concentrations a visibly olive-green color (framed by a: Haliaetus albicilla; c: Circus aeruginosus). This color estimate lies still below the preserved bluish shimmer of the eggshells. Egg colors at cluster edges are extracted from Cassey et al. 2012 and labelled from $\mathrm{a}-\mathrm{h}$. 
375 values for shell porosity were found in the middle portion of the oviraptor egg (zones 2 and 3),

376 and especially pronounced in zone 3 with a resultant conductance of $43.6 \mathrm{mg} \mathrm{H}_{2} \mathrm{O}$ day $^{-1}$ Torr $^{-1}$

377 (Table S5). The pointed end (zone 4) which is stuck in the nest material, has a calculated

378 conductance of $22.88 \mathrm{mg} \mathrm{H}_{2} \mathrm{O}$ day $^{-1}$ Torr $^{-1}$, while the exposed blunt end (zone 1) has a calculated

379 conductance of $13.77 \mathrm{mg} \mathrm{H}_{2} \mathrm{O}$ day $^{-1}$ Torr $^{-1}$ (Table S5).

380

381

\section{DISCUSSION}

382

383

Some aerobic microorganisms are known to produce protoporphyrin as an intermediate of their cytochrome c biosynthesis, and they also use biliverdin which represents a highlyconserved metabolite. Thus, a microbial origin of the pigments that we detected from our oviraptorid egg samples needs to be excluded. We use the double-checking LC MS approach (based on Gorchein et al. 2009) applied to sediment adherent to the oviraptorid eggshells from Jiangxi to reliably exclude any wholesale sample contamination, contamination of the LC MS system, of used laboratory equipment or chemicals. Absence of any traces of BV or PP in our sediment control sample proves the cleanliness of our analytical system and supplies, as it proves absence of whole sample contamination based on potentially abundant microbes in the deposits. The only alternative source of the detected oviraptorid eggshell pigments would be eggshell-only contamination with microbially derived BV and PP (Woodward \& Dailey, 1995). The preserved bluish-greenish shimmer of the investigated eggshells strongly argues against this. Also, the preserved pigment concentrations and differing BV and PP ratios eliminate the possibility of eggshell-only microbial contamination. The preserved concentrations fall within the empirical correction for pigment loss during the extraction routine (see Figure 4). Thus, the most parsimonious conclusion is that we have documented oviraptorid eggshell pigments.

Our results push the origin of pigmented eggshells phylogenetically back to oviraptorid dinosaurs (see Figure 5) (Kilner, 2006). To test for convergent evolution or homology of egg color between oviraptorids and crown birds, future investigations of pigmentation in other eumaniraptoran eggshells are required. Oviraptorid dinosaurs incorporated the same pigments and isoforms into their eggshells, out of a pool of dozens of possible staining secondary metabolites (McGraw et al., 2006; Hubbard et al., 2010; Stoddard \& Prum, 2011). If dinosaur egg color was a convergent character relative to the colored eggs of crown birds, the same color effect could have been achieved by use of different metabolites. Non-avian dinosaurs and 
406 modern birds apparently use the same molecules to create eggshell coloration. There are no

407 studies available testing for pigment constraints during the shell formation based on

408 simultaneous shell crystallite growth and pigment incorporation into the eggshell organic matrix.

409 Also, potential constraints of metabolite transport mechanisms or de novo synthesis sites in the

410 archosaur shell gland are yet unknown, as is metabolite permeability through the archosaur shell

411 gland wall. In any case, we can infer based on our results that oviraptor shell glands generally

412 worked in a similar way avian shell glands do: due to its hydrophilic behavior biliverdin is

413 preferentially incorporated into the organic matrix of the eggshell prismatic zone which holds the

414 calcite crystallites (Falk, 1964). Biomaterial studies suggested thioether linkage of BV to

415 cysteine-rich proteins, allowing an energy-efficient storage close to the ion lattice of calcite

416 crystals (Lamparter et al. 2004; Salewski et al., 2013). Based on this presumably general storage

417 mechanism of BV in biocomposite materials, we infer a similar storage in oviraptor eggshells.

418 PP is secreted during the final steps of eggshell formation, while the storage mechanism is yet

419 unclear. Due to its hydrophobic properties, PP is currently thought to occur in highest

420 concentrations in the waxy eggshell cuticle (Baird et al., 1975). Thus, evidence for PP in fossil

421 oviraptorid eggshells strengthens the support for hypothesized preservation of eggshell cuticle

422 through deep time (Mikhailov, 1991; Schweitzer et al. 2002; Varricchio and Jackson 2004). Both

423 pigments are supposed to be synthesized de novo in the shell gland tissue (Wang et al., 2009).

424 Combining our pigment analyses with the outcomes of studies on oviraptorid clutch

425 arrangements (Huh et al. 2014, Pu et al. 2017), it can be summed up that oviraptorid eggs were

426 most probably laid in overlapping circles, partially stuck in the nesting material, with their blunt

427 ends exposed, pointing upwards in an almost vertical orientation. Partially exposed, blue-green

428 eggs, stacked in circular layers, allow the inference of a similarly colored nesting material. In

429 modern birds, blue-green eggs stored in ground nests are found in Casuariformes, including

430 emus and cassowaries (Coombs, 1989). Emus and cassowaries lay their eggs in soil mounds

431 covered with leaf litter and vegetation, so that egg color and nesting background match in tone

432 (Coombs et al., 1989). Considering arid to subtropical paleoclimate reconstructions for Late

433 Cretaceous China (Hsu, 1983), and the fluvial/alluvial red silt-sandstone sedimentology of the

434 fossil laegerstaetten from Henan, Jiangxi and Guangdong provinces, vegetation coverage of the

435 nest base comparable to emu and cassowary nests, adjacent to permanent or rather ephemeral

436 river systems would offer an environment requiring blue-greenish egg colors for nest crypsis. An 
437 alternative explanation to only cryptic functions of blue-green eggs has been described for 438 tinamous (Tinamus major): blue-green eggs in tinamous (Tinamus major) have been

439 demonstrated to be non-cryptic and to be laid in environments where the egg color significantly

440 contrasts the nesting background color (Brennan, 2010). In tinamous, nest predation depends not 441 on egg color cues, but mainly on either visual or chemical parental cues during clutch incubation, 442 and egg color is supposed to have evolved for intraspecific signaling (Brennan, 2010).

443 Intraspecifically, blue-green egg color in modern birds has been associated with paternal care, 444 communal nesting, and postmating sexual signaling (Moreno \& Osorno, 2003; Handfort \& 445 Mares, 1985). Paternal care was previously hypothesized to have dinosaur origin, tracing back to 446 oviraptorid dinosaurs, and thus, poses a good fit our finding of oviraptorid blue-green egg color 447 (Varricchio et al. 2008, but see Birchard et al. 2013). Communal nesting, as seen in polyandrous 448 birds like emus and cassowaries, represents a reproductive strategy that might apply for non449 avian dinosaurs, but has never been tested for (Handfort \& Mares, 1985). Preliminary studies 450 based on eggshell chemical signatures identifying multiple maternal individuals contributing 451 eggs to one clutch hint at communal nesting in oviraptorid dinosaurs (Yang et al., 2016). Finally, 452 postmating sexual signaling according to the Sexual Signaling Hypothesis appears controversial 453 in the ornithological literature (Moreno \& Osorno, 2003; Krist \& Grim, 2007). This hypothesis 454 suggests intensive blue-green egg color as a quality marker for maternal health and 455 immunocapability (Moreno \& Osorno, 2003). Post-mating sexual signaling then occurs due to 456 BV being incorporated in high concentrations into the eggshell because it is dispensible to the 457 maternal metabolism (Moreno \& Osorno, 2003). The general idea goes back to the handicap 458 hypothesis (Roberts et al., 2004), and assumes that the male is motivated by the confirmation of 459 the female health status and thus, the offspring quality (Moreno \& Osorno, 2003).

460 The similarity in reproductive strategies between crown birds and derived non-avian 461 maniraptorans may reflect shared selective pressures: the recent discovery of the anseriform 462 Vegavis in Late Cretaceous deposits from Antarctica provides evidence that crown birds 463 coexisted with non-avian dinosaurs (Clarke et al., 2016). The presence of neognath birds in the 464 Late Cretaceous implies that paleognath birds already diverged at this point (based on avian 465 phylogeny by Prum et al., 2015). We would like to suggest new avenues of research based on the 466 perspective of the potential coexistence, shared selection pressures, and niche competition of 467 secondarily flightless paleognath birds and oviraptorid, dromeosaurid, and troodontid dinosaurs. 


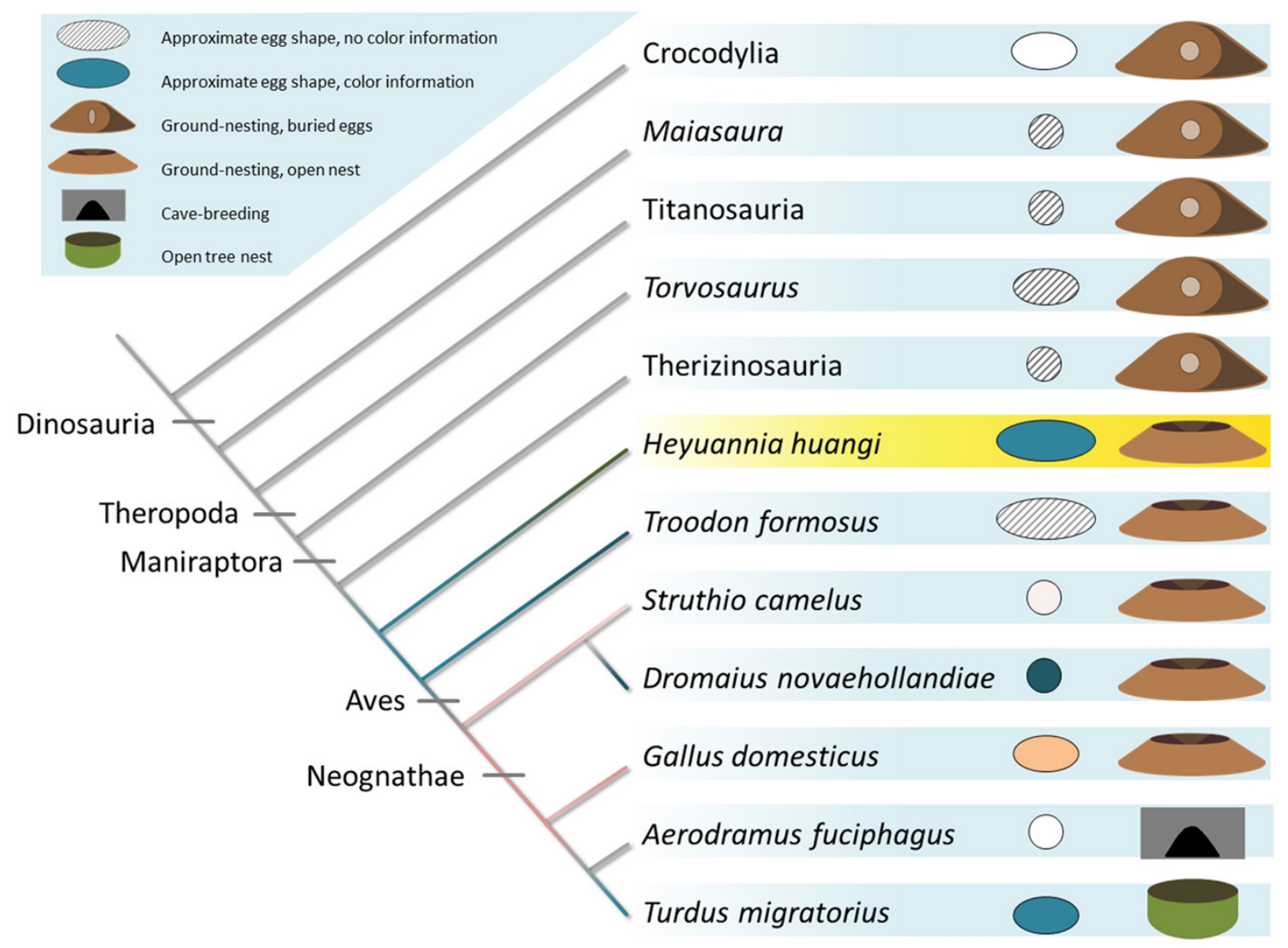

468

469

470

471

472

473

474

475

476

477

478

479

480

481

482

483

484

\section{5}

486

487

Figure 5 Evolution of egg coloration (egg item), egg shape (egg item), and nesting type (nest item) in archosaurs. Listed (as successive outgroups) are ornithischian dinosaurs, such as Maiasaura, for sauropods, such as titanosaurs, and theropod dinosaurs, including Torvosaurus, therizinosaurs, oviraptors, troodontids, and crown birds (Varricchio \& Jackson 2016). The topology of the tree is based on Nesbitt, 2011(Archosauria), Sereno, 1999 (Dinosauria), Carrano et al., 2012 (Tetanurae), Turner et al., 2012

(Paraves), Prum et al., 2015 (Aves). Porosity data and clutch structure indicate a fully buried nesting type for most dinosaur taxa (Varricchio \& Jackson 2016). Buried eggs which are indicated by the nesting item next to the egg item for each terminal taxon appear to be plesiomorphic. Oviraptorid dinosaurs, here represented by Heyuannia huangi, built at least partially open nests, concurrent with the phylogenetically most basal appearance of PP and BV in dinosaur eggshell (egg item). In modern birds, eggshell pigmentation varies with nesting microenvironment. Presence and kind of the (more abundant) eggshell pigment is represented by the color of the cladogram branch, and the egg item next to each terminal taxon. Beige egg colors indicate PP being more abundant, whereas bluish egg colors indicate BV being more abundant.

\section{CONCLUSIONS}

Our study extends the origin of colored eggs from crown birds to oviraptorid dinosaurs.

The result has important implication both for the origin of avian biology and the reproductive 
488 biology of theropods dinosaurs. This work also broadens the scope of paleontological research

489

490

491

492

493

494

495

496

497

498

499

500

501

502

503

504

505

506

507

508

509

510

511

512

513

514

515

517 516 hard tissue taphonomy.

518 Supplemental Information

on molecular preservation and ecology to hard vertebrate tissues. Our study ties together previous hypotheses on the eumaniraptoran origin of partially open nesting, and paternal care. Also, potential future avenues for investigation are posed by the potential linkage between bluegreen egg color and communal nesting, as well as polyandry, which represent yet unaddressed topics in extinct archosaurs.

The second aspect of our work focuses on its implications for molecular and soft tissue preservation through deep time. Chemically stable, relatively small biological molecules such as $\mathrm{PP}$ and BV appear to be protected from complete degradation over millions of years in carbonate biomineral matrices, in an oxidative sediment milieu. Similar biomolecule preservation may also be present in enamel, dentine and bone mineral. Ancient biomolecules and the soft tissues which they construct pave the way to trace life and its behaviors through time and, thus, invite further studies since they are easily detectable, more abundant than expected, and revolutionary in their ecological implications.

\section{ACKNOWLEDGEMENTS}

We thank Y.-N. Cheng (NMNS), Y.-F. Shiao (PFMM), T. Töpfer (ZFMK) and X. Wu $(\mathrm{CMN})$, who provided expertise and the eggshell specimens which are not from the collections of the Steinmann Institute. M. Famulok (LIMES Institute, University of Bonn) provided additional laboratory facilities. We would like to acknowledge D. E. G. Briggs (Yale University) for editing this manuscript, M. Fabbri (Yale University) for proofreading the non-avian dinosaur statements made in this paper, and R. O. Prum (Yale University) for improving our ornithological inferences. Many thanks also to D. Bartha (AMNH), G. Mayer (Senckenberg Museum Frankfurt), D. J. Varricchio (MSU), M. A. Norell (AMNH), J. Vinther (University of Bristol), S. Portugal (University of London), M. Hauber (Hunter College), \& all participants of the Society of Experimental Biology Eggshell Symposium 2015 for constructive discussions that improved this study. We would like to thank the Society of Vertebrate Paleontology and S.

515 Cohen for their interest and support of future research on the evolution of eggshell coloration and 
519 Supplemental information for this article is available (PeerJ).

520

521

522

REFERENCES

523 Baird, T., Solomon, S. E., \& Tedstone, D. R. (1975). Localisation and characterisation of egg shell porphyrins in several avian species. British poultry science, 16(2), 201-208.

525

526

527

528

529

530

531

532

533

534

535

536

537

538

539

540

541

542

543

544

545

546

547

548

Birchard, G. F., Ruta, M., \& Deeming, D. C. (2013). Evolution of parental incubation behavior in dinosaurs cannot be inferred from clutch mass in birds. Biology Letters 9, 20130036.

Brennan, P. L. (2010). Clutch predation in great tinamous Tinamus major and implications for the evolution of egg color. Journal of Avian Biology, 41(4), 419-426.

Carrano, M. T., Benson, R. B., Sampson, S. D. (2012). The phylogeny of Tetanurae (Dinosauria: Theropoda). Journal of Systematic Palaeontology 10(2), 211-300.

Cassey, P., Thomas, G. H., Portugal, S. J., Maurer, G., Hauber, M. E., Grim, T., Lovell, P. G., Mikšik, I. (2012). Why are birds’ eggs colourful? Eggshell pigments co-vary with lifehistory and nesting ecology among British breeding non-passerine birds. Biological Journal of the Linnean Society of London 106, 657-672.

Castilla, A. M., Dhondt, A. A., Díaz-Uriarte, R., \& Westmoreland, D. (2007). Predation in Ground-Nesting Birds: an Experimental Study Using Natural Egg-Color Variation Prédation chez les oiseaux nichant au sol: étude expérimentale fondée sur la variation naturelle de la coloration des œufs. Avian Conservation and Ecology-Écologie et conservation des oiseaux, 2(1), 2.

Cheng, Y., Qiang, J., Wu, X., Shan, H. (2008). Oviraptorosaurian eggs (Dinosauria) with embryonic skeletons discovered for the first time in China. Acta Geologica Sinica 82(6), 1089-1094.

Cherry, M. I., Gosler, A. G. (2010). Avian eggshell coloration: new perspectives on adaptive explanations. Biological Journal of the Linnean Society of London 100(4), 753-762.

Clarke, J. A., Chatterjee, S., Li, Z., Riede, T., Agnolin, F., Goller, F., \& Novas, F. E. (2016). Fossil evidence of the avian vocal organ from the Mesozoic. Nature.

Coombs, W. P. (1989). Modern analogs for dinosaur nesting and parental behavior. Paleobiology of the Dinosaurs. Books on Demand, Boulder, Colo, 21-53. 
549 Deeming, D. C. (2006). Ultrastructural and functional morphology of eggshells supports the idea 550 that dinosaur eggs were incubated buried in a substrate. Palaeontology 49(1), 171-185.

551 Endler, J. A. (1978). A predator's view of animal color patterns. In Evolutionary biology (pp. 552 319-364). Springer US.

553 Erben, K. H. (1995). The Cretaceous/Tertiary boundary in the Nanxiong-Basin (continental 554 facies, SE-China). Stuttgart: Franz Steiner Verlag.

555 Falk, J. E. (1964). Porphyrins and metalloporphyrins (Vol. 2, pp. 72-93). Amsterdam: Elsevier.

556 Ferguson, M. W. (1982). The structure and composition of the eggshell and embryonic

557 membranes of Alligator mississippiensis. Journal of Zoology, 36(2), 99-152.

558 Fernández, M. S., García, R. A., Fiorelli, L., Scolaro, A., Salvador, R. B., Cotaro, C. N., Kaiser, G. W., \& Dyke, G. J. (2013). A large accumulation of avian eggs from the Late Cretaceous of Patagonia (Argentina) reveals a novel nesting strategy in Mesozoic birds. PLoS ONE 8(4): e61030. doi:10.1371/journal.pone.0061030

562

563

564

565

566

567

568

569

570

571

572

573

574

575

576

577

578

Gillis, H., Gauffre, B., Huot, R., \& Bretagnolle, V. (2012). Vegetation height and egg coloration differentially affect predation rate and overheating risk: an experimental test mimicking a ground-nesting bird. Canadian Journal of Zoology, 90(6), 694-703.

Gorchein, A., Lim, C. K., \& Cassey, P. (2009). Extraction and analysis of colourful eggshell pigments using HPLC and HPLC/electrospray ionization tandem mass spectrometry. Biomedical Chromatography, 23(6), 602-606.

Gosler, A. G., Higham, J. P., \& Reynolds, S. J. (2005). Why are birds' eggs speckled? Ecology Letters 8(10), 1105-1113.

Greenwalt, D. E., Gorevab, Y. S., Siljeström, S. M., Rose T., \& Harbach, R. E. (2013). Hemoglobin-derived porphyrins preserved in a middle Eocene blood-engorged mosquito. Proceedings of the National Academy of Sciences of the USA 110, 18496-18500.

Handford, P., \& Mares, M. A. (1985). The mating systems of ratites and tinamous: an evolutionary perspective. Biological Journal of the Linnean Society, 25(1), 77-104.

Hirsch, K. F., Quinn, B. 1990. Eggs and eggshell fragments from the Upper Cretaceous Two Medicine Formation of Montana. Journal of Vertebrate Paleontology 10(4), 491-511.

Hsu, J. (1983). Late Cretaceous and Cenozoic vegetation in China, emphasizing their connections with North America. Annals of the Missouri Botanical Garden, 490-508. 
579 Hubbard, J. K., Uy, J. A. C., Hauber, M. E., Hoekstra, H. E., \& Safran, R. J. (2010). Vertebrate

580

581

582

583

584

585

586

587

588

589

590

591

592

593

594

595

596

597

598

599

600

601

602

603

604

605

606

607

608

609

pigmentation: from underlying genes to adaptive function. Trends in Genetics, 26(5), 231239.

Huh, M., Kim, B. S., Woo, Y., Simon, D. J., Paik, I. S., \& Kim, H. J. (2014). First record of a complete giant theropod egg clutch from Upper Cretaceous deposits, South Korea. Historical Biology, 26(2), 218-228.

Igic, B., Greenwood, D. R., Palmer, D. J., Cassey, P., Gill, B. J., Grim, T., Brennan, P. L. R., Bassett, S. M., Battley, P. F., \& Hauber, M. E. (2009). Detecting pigments from colourful eggshells of extinct birds. Chemoecology 20, 43-48.

Ishikawa, S., Suzuki, K., Fukuda, E., Arihara, K., Yamamoto, Y., Mukai, T., \& Itoh, M. (2010). Photodynamic antimicrobial activity of avian eggshell pigments. FEBS Letters 584(4), 770-774.

Jackson, F. D., Varricchio, D. J., Jackson, R. A., Vila, B., \& Chiappe, L. (2008). Water vapor conductance of a titanosaur egg (Megaloolithus patagonicus) from Argentina: comparison with a Megaloolithus siruguei egg from Spain. Paleobiology 34(2), 229-246.

Kennedy, G. Y., \& Vevers, H. G. (1975). A survey of avian eggshell pigments. Comparative Biochemistry and Physiology Part B 55B(1), 117-123.

Kilner, R. M. (2006). The evolution of egg colour and patterning in birds. Biological reviews of the Cambridge Philosophical Society 81(3), 383-406.

Komdeur, J., \& Kats, R. K. (1999). Predation risk affects trade-off between nest guarding and foraging in Seychelles warblers. Behavioral Ecology, 10(6), 648-658.

Krist, M., \& Grim, T. (2007). Are blue eggs a sexually selected signal of female collared flycatchers? A cross-fostering experiment. Behavioral Ecology and Sociobiology, 61(6), 863-876.

Kubo, Y., \& Furusawa, I. (1991). Melanin biosynthesis. In The fungal spore and disease initiation in plants and animals (pp. 205-218). Springer US.

Kurochkin, E. N., Chatterjee, S., \& Mikhailov, K. E. (2013). An embryonic enanthiornithine bird and associated eggs from the Cretaceous of Mongolia. Paleontological Journal 47(11), 1252-1269.

Lahti, D. (2008). Population differentiation and rapid evolution of egg colour in accordance with solar radiation. The Auk 125(4), 796-802. 
610 Lamparter, T., Carrascal, M., Michael, N., Martinez, E., Rottwinkel, G., \& Abian, J. (2004). The 611 biliverdin chromophore binds covalently to a conserved cysteine residue in the N-terminus 612 of Agrobacterium phytochrome Agp1. Biochemistry, 43(12), 3659-3669.

613 Leavitt, P. R. (1993). A review of factors that regulate carotenoid and chlorophyll deposition and 614 fossil pigment abundance. Journal of Paleolimnology, 9(2), 109-127.

615 Leighton, P. A., Horrocks, J. A., \& Kramer, D. L. (2009). How depth alters detection and capture 616 of buried prey: exploitation of sea turtle eggs by mongooses. Behavioral Ecology, arp139.

617 Liu, Y. (1999) Classification and stratigraphic position of dinosaurian eggs in Jiangxi. Jiangxi $618 \quad$ Geology 13(1), 3-7.

619 McGraw, K. J. (2006). Mechanics of uncommon colors: pterins, porphyrins, and psittacofulvins. 620 Bird coloration, 1, 354-398.

Mikhailov, K. E., Bray, E. S., \& Hirsch, K. F. (1996). Parataxonomy of fossil egg remains 622 623 (Veterovata): principles and application. Journal of Vertebrate Paleontology 16(4), 763769.

Mikšík, I., Holáň, V. \& Deyl, Z. (1996). Avian eggshell pigments and their variability. Comp. Biochem. Physiol. 113B, 607-612.

Morales, J., Torres, R., \& Velando, A. (2010). Parental conflict and blue egg coloration in a seabird. Naturwissenschaften 97(2), 173-180.

628

Moreno, J., \& Osorno, J. L. (2003). Avian egg colour and sexual selection: does eggshell pigmentation reflect female condition and genetic quality?. Ecology Letters, 6(9), 803-806.

Nesbitt, S. J. 2011. The early evolution of archosaurs: relationships and the origin of major clades. Bulletin of the American Museum of Natural History, 1-292.

Norell, M. A., Clark, J. M., Chiappe, L. M., \& Dashzeveg, D. (1995). A nesting dinosaur. Nature, 378(6559), 774.

634 Packard, M., \& Seymour, R. (1997). Evolution of the amniote egg. Academic Press.

635 Prum, R. O., Berv, J. S., Dornburg, A., Field, D. J., Townsend, J. P., Lemmon, E. M., \& Lemmon, A. R. (2015). A comprehensive phylogeny of birds (Aves) using targeted nextgeneration DNA sequencing. Nature.

638 Pu, H., Zelenitsky, D. K., Lü, J., Currie, P. J., Carpenter, K., Xu, L., Koppelhus, E.B., Jia, S., Xiao, L., Chuang, H., Li, T., Kundrat, M., \& Shen, C. (2017). Perinate and eggs of a giant 
640

641

642

643

644

645

646

647

648

649

650

651

652

653

654

655

656

657

658

659

660

661

662

663

664

665

666

667

668

669

670

caenagnathid dinosaur from the Late Cretaceous of central China. Nature Communications, 8,14952 .

Rimington, C. (1939). A reinvestigation of turacin, the copper porphyrin pigment of certain birds belonging to the Musophagidae. Proceedings of the Royal Society of London. Series B, Biological Sciences, 106-120.

Roberts, M. L., Buchanan, K. L., \& Evans, M. R. (2004). Testing the immunocompetence handicap hypothesis: a review of the evidence. Animal Behaviour, 68(2), 227-239.

Ryter, S. W., \& Tyrrell, R. M. (2000). The heme synthesis and degradation pathways: role in oxidant sensitivity: heme oxygenase has both pro-and antioxidant properties. Free Radical Biology and Medicine, 28(2), 289-309.

Salewski, J., Escobar, F. V., Kaminski, S., von Stetten, D., Keidel, A., Rippers, Y., \& Frankenberg-Dinkel, N. (2013). Structure of the biliverdin cofactor in the Pfr state of bathy and prototypical phytochromes. Journal of Biological Chemistry, 288(23), 16800-16814.

Sato, T., Cheng, Y., Wu, X., Zelenitsky, D. K., Hsiao, Y. (2005). A pair of shelled eggs inside a female dinosaur. Science 308, 375.

Schweitzer, M. H., Jackson, F. D., Chiappe, L., Schmitt, J. G., Calvo, J. O., \& Rubilar, D. E. (2002). Late Cretaceous avian eggs with embryos from Argentina. Journal of Vertebrate Paleontology 22, 191-195.

Sereno, P. C. (1999). The evolution of dinosaurs. Science 284 (5423), 2137-2147.

Stoddard, M. C., \& Prum, R. O. (2011). How colorful are birds? Evolution of the avian plumage color gamut. Behavioral Ecology, arr088.

Stoddard, M. C., Kupán, K., Eyster, H. N., Rojas-Abreu, W., Cruz-López, M., Serrano-Meneses, M. A., \& Küpper, C. (2016). Camouflage and Clutch Survival in Plovers and Terns. Scientific Reports, 6.

Turner, A. H., Makovicky, P. J., \& Norell, M. A. (2012). A review of dromaeosaurid systematics and paravian phylogeny. Bulletin of the American Museum of Natural History, 1-206.

Varricchio, D. J., Jackson, F., Borkowski, J. J., \& Horner, J. R. (1997). Nest and egg clutches of the dinosaur Troodon formosus and the evolution of avian reproductive traits. Nature 385, 247-250.

Varricchio, D. J., Moore, J. R., Erickson, G. M., Norell, M. A., Jackson, F. D., \& Borkowski, J. J. (2008). Avian paternal care had dinosaur origin. Science 322, 1826-1828. 
671 Wang, X. T., Zhao, C. J., Li, J. Y., Xu, G. Y., Lian, L. S., Wu, C. X., \& Deng, X. M. (2009).

672

673

674

675

676

677

678

679

680

681

682

683

684

685

686

687

688
Comparison of the total amount of eggshell pigments in Dongxiang brown-shelled eggs and Dongxiang blue-shelled eggs. Poultry Science 88(8), 1735-1739.

Watt, A. A., Bothma, J. P., \& Meredith, P. (2009). The supramolecular structure of melanin. Soft Matter, 5(19), 3754-3760.

Wiemann, J., Fabbri, M., Yang, T.-R., Vinther, J., Stein, K., Geisler-Wierwille, T., Briggs, D. E. G., \& Sander, P. M. (2016). From White to Black: Maillard Products and Endogenous Porphyrins Stain Fossil Vertebrate Hard Tissues. Podium Symposium on Molecular Paleontology, Annual Meeting of the Society of Vertebrate Paleontology 2016.

Woodard, S. I., \& Dailey, H. A. (1995). Regulation of heme biosynthesis in Escherichia coli. Archives of biochemistry and biophysics, 316(1), 110-115.

Yang, T.-R., Wiemann, J., Xu, L., Cheng, J.-N., \& Wu, X.-C. New evidence from complete oviraptorid egg clutches suggests a peculiar nest architecture and alternative explanation for adult-associated clutches. Submitted.

Zhao, Z. Q., Ye, J., Li, H. M., Zhao, Z. H., \& Yan, Z. (1991). Extinction of the dinosaurs across the Cretaceous Tertiary boundary in Nanxiong Basin Guangdong Province, Vertebrata Palasiatica 29(1), 1-20. 